Article

\title{
Life Cycle Analysis of Double-Arm Type Robotic Tools for LCD Panel Handling
}

\author{
Heather Wyatt, Allan Wu, Rami Thomas and Yuelei Yang * \\ Department of Mechanical, Manufacturing and Automotive Engineering, University of Ontario, Institute of \\ Technology, Oshawa, ON L1H 7K4, Canada; heather.wyatt@uoit.net (H.W.); allan.wu@uoit.net (A.W.); \\ rami.thomas@uoit.net (R.T.) \\ * Correspondence: yuelei.yang@uoit.ca; Tel.: +1-905-721-8668 (ext. 2880)
}

Academic Editor: Dan Zhang

Received: 31 December 2016; Accepted: 2 March 2017; Published: 4 March 2017

\begin{abstract}
This study includes a life cycle assessment of double-arm type robotic tools made with three different materials. The robotic arms are used for Liquid Crystal Display (LCD) panel handling. The environmental impacts generated during all the life stages of the robots have been investigated. The study shows that composite materials have less environmental impact compared with metallic materials. It is also found that the most significant impact category generated by the robotic tools is carcinogen, while the use stage of the robotic tool's life cycle has the greatest environmental impact.
\end{abstract}

Keywords: robotic tool; life cycle assessment; green manufacturing; environmental impact

\section{Introduction}

Sustainability and environmental impact have quickly become critical issues in the manufacturing industry and the awareness of green manufacturing has led engineers to be more and more environmentally conscious. Due to their precision and accuracy, the robotic tools have been widely used in various manufacturing industries [1-3]. Although they are generally treated as contributors to the green manufacturing because application of these robotic tools has significantly improved the productivity and reduced the energy and material consumption, the exact role of the robotic tools in the green manufacturing still needs to be thoroughly investigated. In this paper, a life cycle assessment of various concepts of a double-arm type robotics for Liquid Crystal Display (LCD) panel handling will be conducted. The environmental aspects and potential impacts associated with the pre-manufacturing, manufacturing, use, and end of life of the robotic tools for LCD panel handling will be assessed.

Modern manufacturers of the LCD panels have used a method which combines automation and production line workers. The production procedure can be divided into six stages: assembly, aging, adjustment, white balance and Digital Uniformity Equalizer (DUE) adjustment, testing, and packaging [4]. For different manufacturers, these robotic tools may have different levels of involvement during these stages, but the mechanism of these robotic tools is similar. A typical robotic system used for loading and unloading the glass panels usually has the following components: a base, two arms, two wrists and end effectors (hands) [5].

\section{Methodology}

\subsection{Goal and Scope}

The main objective of this study is to provide a Life Cycle Analysis (LCA) for the robotic tools which can handle LCD panels for the manufacturers but are made with different materials. To fully describe the material and energy requirements for each robotic tool option, this study used cited values or calculated data to conduct an analysis. 
The functional unit is set as years of use, which is a standard unit of measure when service delivered is measured by time. In this study, the expected service life for the robotic arms is assumed to be eight years, which is based on the average service life of industrial robots [6].

The goals of this LCA case study include to understand which eco-design strategies result in the greatest environmental performance improvement; to identify which stage will pose the greatest environmental impact during the whole life of the robotic tools; and to determine how the results can be used to better define the functional requirements and design parameters for the robotic tools in the product realization process.

\subsection{System Boundaries}

In this study, the double-arm type robotic tools used for LCD handling are manufactured in a Japanese owned facility located in Taiwan. The manufactured robotic tools are then transported by truck to the Kaohsiung Port in Taiwan and shipped to Yosu Port in South Korea by ocean freighter; finally, they will be delivered by truck to Samsung Tangjeong Industrial Complex, which includes a facility dedicated to the joint collaboration of Samsung and Sony of producing LCD panels. The double-arm type robots are expected to remain in the Samsung Tangjeong Industrial Complex in South Korea for their service life, estimated to be eight years. Table 1 shows the distances from the location of the manufacturer of the robotic arms to the location of its user, a LCD panel producer.

Table 1. Distances from the manufacturer of the robot to the LCD panel producer.

\begin{tabular}{lll}
\hline Description & Transportation Mode & Distance \\
\hline $\begin{array}{l}\text { From the manufacturer of the robotic arms to } \\
\text { Kaohsiung Port, Taiwan }\end{array}$ & Trucked via 28-ton truck & $7 \mathrm{~km}$ \\
\hline Kaohsiung Port, Taiwan to Yosu Port, South Korea & Ocean freighter & $\begin{array}{l}1590.87 \mathrm{~km} \\
\text { (859 nautical miles) }\end{array}$ \\
\hline $\begin{array}{l}\text { Yosu Port, South Korea to Samsung Tangjeong } \\
\text { Industrial Complex }\end{array}$ & Trucked via 28-ton truck & $240 \mathrm{~km}$ \\
\hline
\end{tabular}

This LCA study will evaluate the environmental impacts associated with all life stages of the robotic tools, which include the pre-manufacturing stage, manufacturing of the robotic arms, use, as well as disposal, reuse or recycle of the robotic arms. To simplify the analysis, the mechanical components of the robot will be included in the analysis, while electrical components (wiring, sensors) will be excluded due to their relatively small sizes and similarity. Power consumptions of the robotic arms will be calculated based on the anticipated requirement of an appropriately sized motor which can fulfill the functional requirements of a robotic arm.

\subsection{Materials}

Robotic tools made with three different materials are investigated in this study. Table 2 lists the material breakdown of five major components of a robot which is made with composite materials.

Table 2. Material breakdown of the composite double-arm type robot for LCD panel handling.

\begin{tabular}{lll}
\hline Component & Weight & Material(s) \\
\hline & & - Eight-ply high stiffness unidirectional carbon-fiber epoxy \\
& & prepreg (URN300) $(60 \%$ carbon-fiber, 10\% epoxy) \\
End Effectors & $1.36 \mathrm{~kg}$ & - Polyurethane foam core $(15 \%)$ \\
(hands) & $(0.68 \mathrm{~kg}$ each) & - Glass surface veil $(5 \%)$ \\
& & - Nylon edge closures $(5 \%)$ \\
& & - Aluminum inserts $(5 \%)$ \\
\hline
\end{tabular}


Table 2. Cont.

\begin{tabular}{|c|c|c|}
\hline Component & Weight & Material(s) \\
\hline Wrist I & $7.32 \mathrm{~kg}$ & $\begin{array}{l}\text { - High strength carbon-fiber epoxy prepreg (USN150) (URN300) } \\
(60 \% \text { carbon-fiber, } 10 \% \text { epoxy) } \\
\text { - Polyurethane foam core }(15 \%) \\
\text { - } \text { Glass surface veil }(5 \%) \\
\text { - Nylon edge closures }(5 \%) \\
\text { - } \text { Aluminum inserts }(5 \%)\end{array}$ \\
\hline Wrist II & $3.43 \mathrm{~kg}$ & $\begin{array}{l}\text { - High strength carbon-fiber epoxy prepreg (USN150) } \\
\text { - Polyurethane foam core } \\
\text { - Glass surface veil } \\
\text { - Nylon edge closures } \\
\text { - Aluminum inserts }\end{array}$ \\
\hline Arms & $\begin{array}{l}12 \mathrm{~kg} \\
\text { (6 kg each) }\end{array}$ & - Carbon-fiber epoxy composite (70\% carbon-fiber, 30\% epoxy) \\
\hline Base & $70 \mathrm{~kg}$ & - Gray cast iron \\
\hline
\end{tabular}

Although metallic materials were deemed less suitable for the specific application which required strict dimensional tolerances and material characteristics, the environmental effect of replacing the composite materials with aluminum has been examined in this study. Table 3 shows the material breakdown of the aluminum double-arm type robot. The total weight of the aluminum robotic components is $40.01 \mathrm{~kg}$, a $15.9 \mathrm{~kg}$ or roughly $66 \%$ increase over the carbon-fiber epoxy composite counterparts. The increased weight of the aluminum components was assumed to be distributed equally with respect to each component's weight relative to structure.

Table 3. Material breakdown of the aluminum double-arm type robot for LCD panel handling.

\begin{tabular}{lll}
\hline Component & Weight & Material(s) \\
\hline End Effectors (hands) & $2.314 \mathrm{~kg}(1.157 \mathrm{~kg}$ each $)$ & $\bullet$ Aluminum \\
Wrist I & $12.09 \mathrm{~kg}$ & - Aluminum \\
Wrist II & $5.656 \mathrm{~kg}$ & $\bullet$ Aluminum \\
Arms & $19.95 \mathrm{~kg}(9.975 \mathrm{~kg}$ each $)$ & $\bullet$ Aluminum \\
Base & $100 \mathrm{~kg}$ & - Gray cast iron \\
\hline
\end{tabular}

Table 4 shows the material breakdown of a robot whose major components are made with stainless steel. Since, if designed for the same stiffness, an aluminum structure will weigh $48 \%$ of the equivalent structure in steel [4], the weight of the steel structure was scaled to roughly 2.08 times that of the aluminum robotic arm concept. Also, due to the increased weight of the robot components, the weight of the cast iron base is scaled up for the metallic robots.

Table 4. Material breakdown of the steel double-arm type robot for LCD panel handling.

\begin{tabular}{lll}
\hline Component & Weight & Material(s) \\
\hline End Effectors (hands) & $4.8208 \mathrm{~kg}(2.4104 \mathrm{~kg} \mathrm{each})$ & - Stainless steel \\
Wrist I & $25.1875 \mathrm{~kg}$ & - Stainless steel \\
Wrist II & $11.7833 \mathrm{~kg}$ & - Stainless steel \\
Arms & $41.5625 \mathrm{~kg}(20.78125 \mathrm{~kg} \mathrm{each})$ & - Stainless steel \\
Base & $200 \mathrm{~kg}$ & - Gray cast iron \\
\hline
\end{tabular}

\subsection{Manufacturing}

Figures 1-3 show the manufacturing processes of the major components: end effectors, wrists, arms as well as the base. 


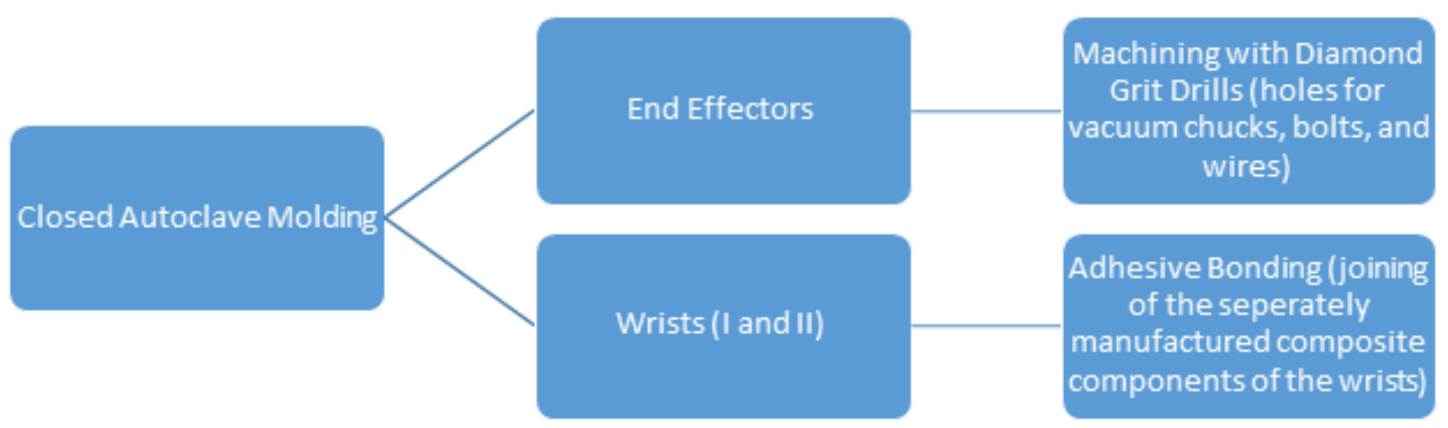

Figure 1. Manufacturing and processing of the end effectors and wrists.

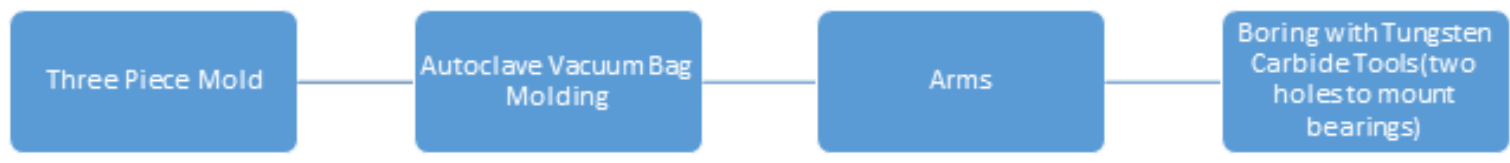

Figure 2. Manufacturing and processing of the arms.

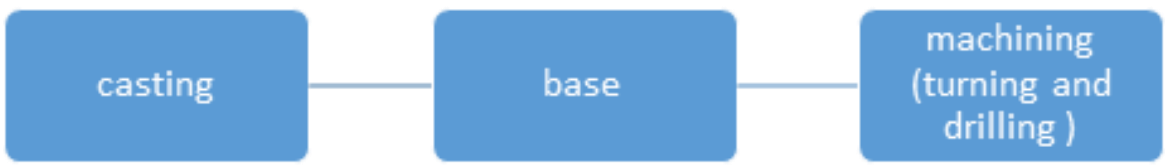

Figure 3. Manufacturing and processing of the base.

\subsection{Power Use}

The power consumption for the LCD panel handling robot is calculated based on the rated power of the drive motors of the arms and wrists. Due to the increased weights and sizes, more powerful motors would be required for those metallic robots, since, for them, not only would the motors have to overcome the increased weight of the metallic components, but the robots themselves would require a larger range of motion to compensate for the larger cassettes. The life operation hours are based on the assumption of twenty hours of operation per day, for a total eight-year life span. Table 5 lists the calculated life energy consumptions of the motors of these robots.

Table 5. Power consumptions of the robots.

\begin{tabular}{ccccc}
\hline Motors & $\begin{array}{c}\text { Rated Power } \\
(\mathbf{W})\end{array}$ & $\begin{array}{c}\text { Materials of Effectors, } \\
\text { Arms and Wrists }\end{array}$ & $\begin{array}{c}\text { Life Operation } \\
\text { (Hours) }\end{array}$ & $\begin{array}{c}\text { Total Energy Use } \\
\text { (kWh) }\end{array}$ \\
\hline Arm drive motor & 466.3 & composite & 58,400 & $27,231.9$ \\
Wrist drive motor & 31.9 & composite & 58,400 & 1862.9 \\
Arm drive motor & 606.2 & Aluminum & 58,400 & $35,401.5$ \\
Wrist drive motor & 41.5 & Aluminum & 58,400 & 2421.8 \\
Arm drive motor & 1262.9 & Stainless steel & 58,400 & $73,753.1$ \\
Wrist drive motor & 85.8 & Stainless steel & 58,400 & 5009.0 \\
\hline
\end{tabular}

\subsection{End of Life}

Composite materials pose a challenge for recycling, as they cannot be economically separated into their component categories. In this study, the composite materials used for the construction of the double-arm type robot (arms, wrists and end effectors) are assumed to be sent to a landfill at the end of the robot's service life, while the base, made of gray cast iron, can be recycled.

By replacing the unrecyclable composite components (arms, wrists and end effectors) with aluminum or steel, recycling of the double-arm type robotic structure becomes feasible. The metallic 
components and the gray cast iron base are assumed to be recycled at the end of the robots' eight-year service life.

\section{Results}

Based on the above assumptions and calculations, a LCA model was built with Sustainable Minds software, and the environmental impact generated by the robotic tools can be calculated. Figure 4 shows the total impact of the robotic tools made with three different materials: composite, aluminum and steel.

\section{Composite}

Total impacts by impact category

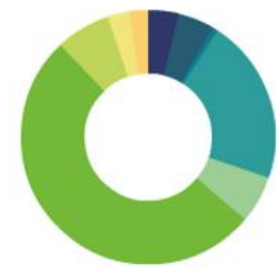

\section{Aluminum}

Total impacts by impact category

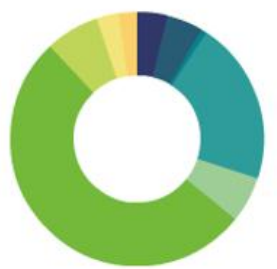

\section{Steel}

Total impacts by impact category

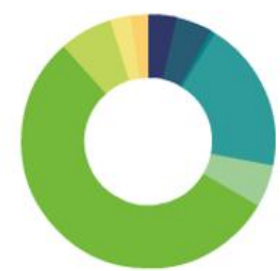

\begin{tabular}{lr}
\hline Impact category & $\%$ \\
\hline Ecological damage & \\
\hline Acidification & 3.94 \\
\hline Ecotoxicity & 4.62 \\
\hline Eutrophication & 0.68 \\
\hline Global warmina & 20.93 \\
\hline Ozone depletion & 0.02 \\
\hline Resource depletion & \\
\hline Fossil fuel depletion & 6.01 \\
\hline Human health damage & \\
\hline Carcinogenics & 51.69 \\
\hline Non carcinogenics & 6.93 \\
\hline Respiratory effects & 2.81 \\
\hline Smog & 2.38 \\
\hline
\end{tabular}

\begin{tabular}{|lr}
\hline Impact category & $\%$ \\
\hline Ecological damage & \\
\hline Acidification & 3.89 \\
\hline Ecotoxicity & 4.64 \\
\hline Eutrophication & 0.67 \\
\hline Global warming & 20.81 \\
\hline Ozone depletion & 0.01 \\
\hline Resource depletion & \\
\hline Fossil fuel depletion & 5.83 \\
\hline Human health damage & \\
\hline Carcinogenics & 52.11 \\
\hline Non carcinogenics & 6.87 \\
\hline Respiratory effects & 2.81 \\
\hline Smog & 2.35 \\
\hline
\end{tabular}

\begin{tabular}{|lr}
\hline Impact category & $\%$ \\
\hline Ecological damage & 3.61 \\
\hline Acidification & 4.58 \\
\hline Ecotoxicity & 0.62 \\
\hline Eutrophication & 19.25 \\
\hline Global warming & 0.01 \\
\hline Ozone depletion & \\
\hline Resource depletion & 5.37 \\
\hline Fossil fuel depletion & \\
\hline Human health damage & 54.98 \\
\hline Carcinogenics & 6.76 \\
\hline Non carcinooenics & 2.64 \\
\hline Respiratorv effects & 2.18 \\
\hline Smog &
\end{tabular}

Figure 4. Total Impact of the robotic arms with three different materials.

The impacts have been divided into three major categories: ecological damage, resource depletion and human health damage. For all three materials, the largest impact category is human health damage, especially the carcinogenic subcategory, which accounts for more than $50 \%$ of the total impacts for all three materials.

Figure 5 shows the environmental impacts generated by the robotic arms during different life stages. The robotic tools made with three different materials have shown a consistent result: the use stage has generated the highest environmental impact.

Figure 6 shows the carbon footprint of the robotic tools during the different life stages. The results are consistent to those shown in Figure 5 for all three robot types; the most carbon emmission was generated during the use stage. 
Impacts by life cycle stage: Total [mPts/func unit]
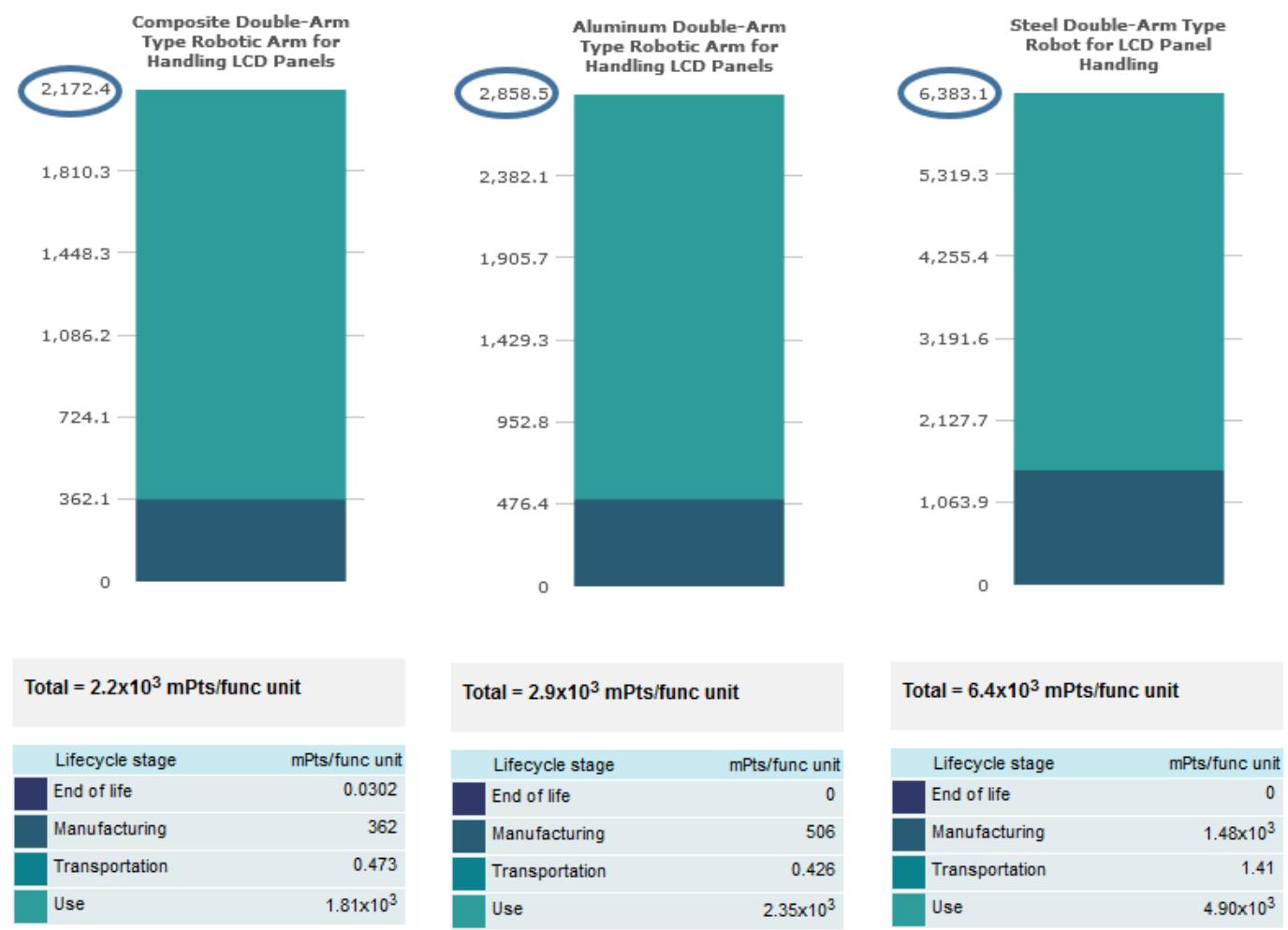

Figure 5. Impacts of the robotic arms by life cyle stage.

\section{Impacts by life cycle stage: Carbon footprint $\left[\mathrm{CO}_{2}\right.$ eq. $\mathrm{kg} /$ func unit $]$}
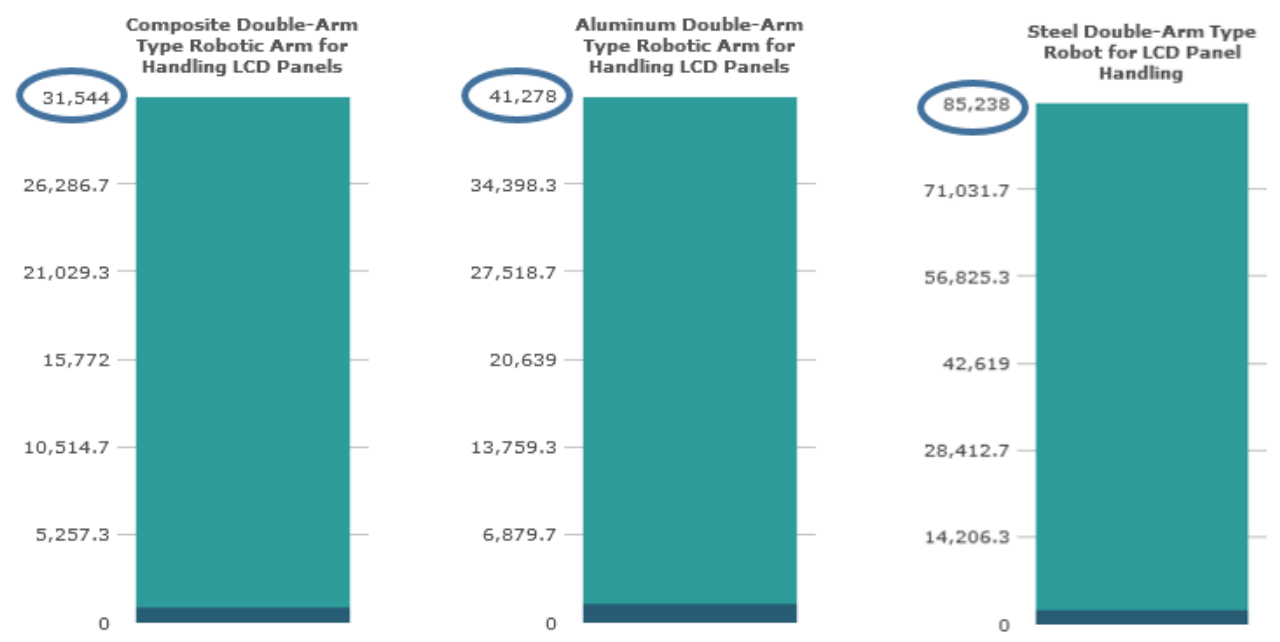

Total $=3.2 \times 10^{4} \mathrm{CO}_{2}$ eq. $\mathrm{kg} /$ func unit

\begin{tabular}{|lr}
\hline Lifecycle stage & $\mathrm{CO}_{2}$ eq. $\mathrm{kg} /$ func \\
unit \\
End of life & 0.739 \\
Manufacturing & 917 \\
Transportation & 6.58 \\
Use & $3.06 \times 10^{4}$
\end{tabular}

Total $=4.1 \times 10^{4} \mathrm{CO}_{2}$ eq. $\mathrm{kg} /$ func unit

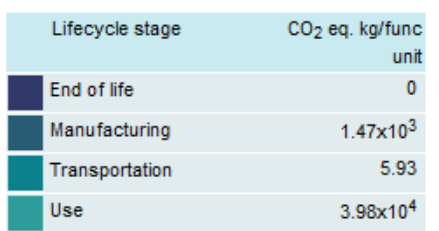

Total $=8.5 \times 10^{4} \mathrm{CO}_{2}$ eq. $\mathrm{kg} /$ func unit

$\begin{array}{lr}\text { Lifecycle stage } & \mathrm{CO}_{2} \text { eq. } \mathrm{kg} / \mathrm{func} \\ \text { unit }\end{array}$

Figure 6. Carbon footprint of three different robotic arms. 
Using eight years as the functional unit (the expected service life for the robotic arms), the kilograms of equivalent carbon dioxide released over the life of the double-arm type robotic tools was thus determined. It will be $32,000 \mathrm{~kg}$ when composite material was selected for the arms, wrists and end effectors; $41,000 \mathrm{~kg}$ when replaced with aluminum (of equivalent strength and damping ability); and $85,000 \mathrm{~kg}$ when replaced with steel (of equivalent strength and damping ability). The aluminum double-arm type robot thus represented an enviromental performance decrease of $32 \%$ from the composite material, and the steel concept represented a decrease of $190 \%$ from the composite material (shown in Figure 7).

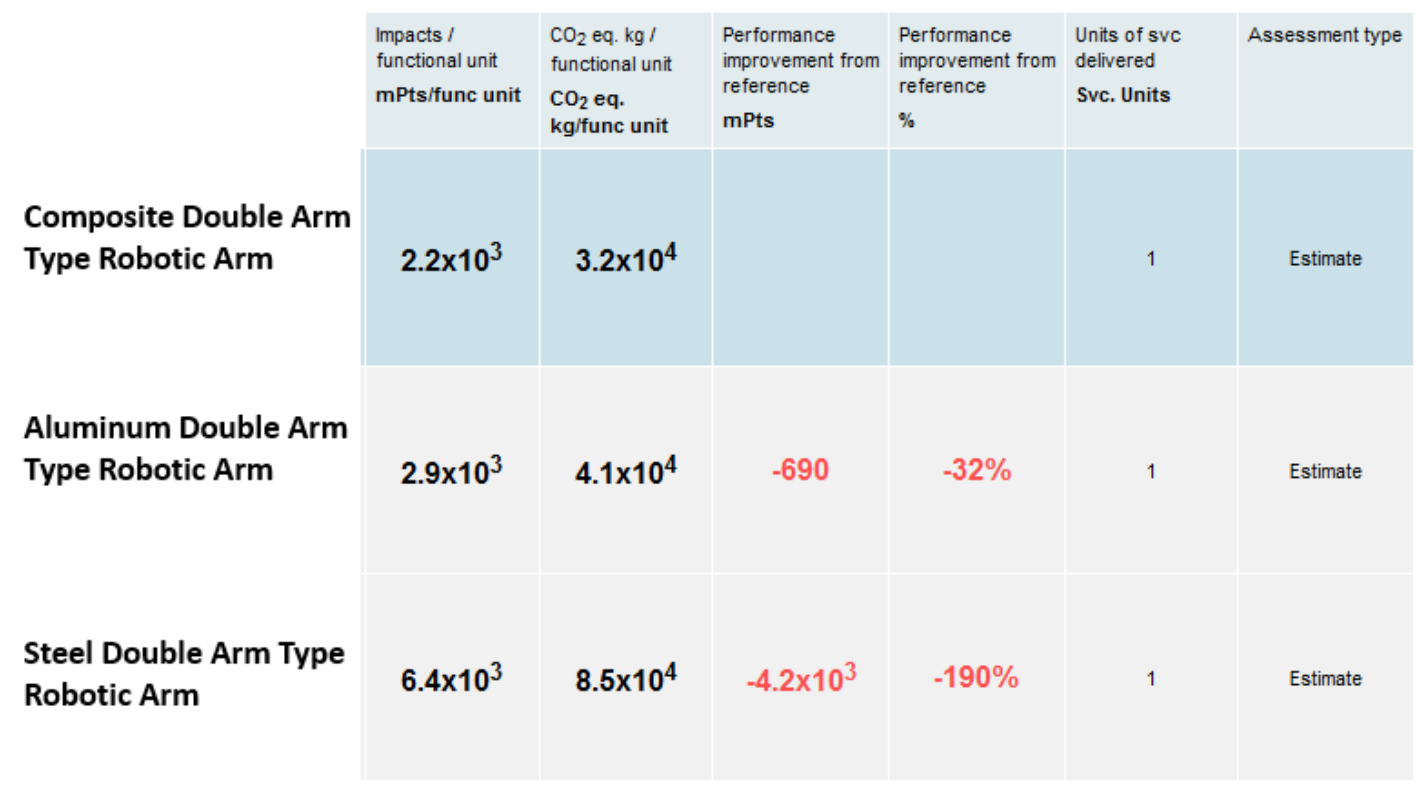

Figure 7. Comparison of environmental impacts of three different robotic arms.

\section{Discussion}

Comparison of the environmental impact of the robotic tools made with three different materials has shown that the greatest impact category is carcinogenic, which is a subgroup of human health damage. For all three robot types, more than $50 \%$ of the total impact identified occurred from them. Human carcinogens are chemicals that alter the genetic structure of human DNA in such a way as to cause abnormal cell growth that the human body cannot counteract [7]. Specifically, carcinogens include chemicals and types of radiation that cause cancer [8]. To reduce the carcinogenic effects of a product, a design mitigation strategy should be adopted to investigate the chemical constituents of the specified materials through their material safety data sheets [9]. In this LCA study, the results show that the composite materials generate less carcinogens compared with metallic materials.

The second most significant environmental impact category, common to all three concepts, is their global warming potential, consisting of approximately $20 \%$ of the total impact. Global warming is the increase of the average temperature of the Earth's atmospheric temperature due to human generated emissions into the air [10]. It is more technically referred to as global climate change, because although the average surface temperature of the Earth increases, some small areas may experience drops in temperature. Design mitigation strategies for reducing global warming effects include improving energy efficiency, switching to non-carbon energy sources (solar, wind, nuclear electricity) or reducing energy use altogether [11]. Minimizing the total life cycle impact requires a compromise of potentially conflicting practices to improve efficiency and use environmentally friendly materials, while being conscious of the end of life methods and their environmental consequences.

The fact that the use stage of the robotic arm's life has the greatest environmental impact reveals that the material selection has significant environmental consequences, which may not have been 
identified if the whole life cycle of the robot had not been considered. Despite having an end of life impact, as a result of being sent to a landfill rather than being recycled, the composite material is still the most ecologically friendly option. The end of life stage of the composite double-arm type robot is responsible for $0.739 \mathrm{CO}_{2}$ eq. $\mathrm{kg} /$ function unit (equivalent kilograms of carbon dioxide emissions), which is dwarfed by the increase in equivalent kilograms of carbon dioxide emissions identified in the use stage of the metallic double-arm type robot options. The use phase was responsible for $95.625 \%$ of the total carbon dioxide equivalent emissions for the composite double-arm type robot, $97.073 \%$ for the aluminum concept, and $97.529 \%$ for the steel concept. The high impact from the use phase supports the reality that many environmental initiatives are aimed at making products more energy efficient. Performing an analysis on a machine used to manufacture other products introduces a new dimension to the high efficiency agenda. Thus, by choosing lighter weight materials with sufficient strength and damping capabilities for the LCD handling task, the power requirement of the direct drive motors used, almost continuously, throughout the eight years of service, will be reduced. Smaller, lighter robotic components made of composite materials are able to accommodate larger LCD panels (the latest trend) while functioning within the current constraints of the cassettes (within which they stack the LCD panels). Redesigning the cassettes to allow access by larger components would require the robot to have a larger range of motion to stack an equal number of LCD panels in the new, larger cassettes. This would necessitate larger, more powerful motors to drive the arms and wrists, decreasing environmental performance due to increased energy consumption and carbon emissions. This LCA study has identified the critical stage of use and the most suitable materials to minimize the environmental impact of robots from cradle to grave.

\section{Conclusions}

LCA analysis of the robotic tools made with three different materials; composite, aluminum and stainless steel, has shown that the most significant impact generated by the robotic arms is carcinogen, while the use stage of the robotic arm's life has the greatest environmental impact. As a subcategory of human health damage, carcinogens accounted for more than $50 \%$ of the total impact for all three materials. During use, the power consumption increased with the weight of the aluminum and steel LCD panel handling robots which offsets the advantage of recycling these materials. With the composite design as the reference, the environmental performance of the LCD panel handling robot decreased $32 \%$ using aluminum and 190\% using steel for the end effectors', wrists' and arms' material. This analysis, performed using Sustainable Minds software, also leads to the conclusion that robotic tools with lighter weight and higher energy efficiency will generate lower environmental impact.

Author Contributions: Heather Wyatt, Allan Wu and Rami Thomas have conducted life cycle analysis, discussed the results and drew the conclusions. Yuelei Yang has contributed to the discussion portion and background review.

Conflicts of Interest: The authors declare no conflict of interest.

\section{References}

1. Fortuna, L.; Gallo, A.; Giudice, G.; Muscato, G. ROBINSPEC: A mobile walking robot for the semi-autonomous inspection of industrial plants. Robot. Manuf. Recent Trends Res. Appl. 1996, 6, 223-228.

2. Coppola, G.; Zhang, D.; Liu, K. A New Class of Adaptive Parallel Robots. Trans. ASME J. Mech. Robot. 2014, 6, 041013-1-041013-11. [CrossRef]

3. Zhang, D. Parallel Robotic Systems and Green Manufacturing. In Proceedings of the TaiShan Academic Forum: The Role of Advanced Robotic Systems in Green Manufacturing, Qingdao, China, 5-7 December 2014.

4. Larsen, R. How a Screen is Manufactured \& Assembled. 2010. Available online: http:/ /www.flatpanelshd. com/focus.php?subaction=showfull\&id=1277885543 (accessed on 28 November 2016).

5. Lee, D.G.; Suh, N.P. Axiomatic Design and Fabrication of Composite Structures; Oxford University Press: New York, NY, USA, 2006.

6. Sharma, P. Lights Out Factory. Available online: http://www.slideshare.net/pankajsharma305/lights-outfactories (accessed on 21 November 2016). 
7. Liberg, A.; Rosqvist, M.; Farnsworth, A. Green robots: Robot-based automation is enabling energy efficiency in the plastics industry. ABB Rev. 2009, 1, 63-67.

8. Cook, J. 10 Industrial Robot Applications. 10 October 2014. Available online: http:/ /www.eetimes.com/ document.asp?doc_id=1324004 (accessed on 19 November 2016).

9. Brumson, B. A Look at Robots in Alternative Energy. Robotic Industry Association, 900 Victors Way, Suite 140, Ann Arbor, Michigan, USA 48108. 1 November 2010. Available online: http:/ / www.robotics.org/content-detail. cfm/Industrial-Robotics-Industry-Insights/A-Look-at-Robots-in-Alternative-nergy/content_id/2433 (accessed on 24 November 2016).

10. Sustainable Minds. Global Warming, Sustainable Minds. Available online: https://app.sustainableminds. com/helpview / 53 (accessed on 25 November 2016).

11. Withgott, J.; Brennan, S.; Murck, B. Environment: The Science Behind the Stories; Pearson: Toronto, ON, Canada, 2013.

(C) 2017 by the authors. Licensee MDPI, Basel, Switzerland. This article is an open access article distributed under the terms and conditions of the Creative Commons Attribution (CC BY) license (http:/ / creativecommons.org/licenses/by/4.0/). 